\title{
Decision value signals in the ventromedial prefrontal cortex and anhedonia across mood and psychotic disorders
}

\author{
Min Su Kang ${ }^{1}$, Daniel H. Wolf ${ }^{2}$, Rebecca Kazinka ${ }^{1,3}$, Sangil Lee ${ }^{1}$, Kosha Ruparel $^{2}$, \\ Mark A. Elliott ${ }^{4}$, Claudia F. Baldassano ${ }^{2},{\text { Anna } \mathrm{Xu}^{2} \text {, Matthew Cieslak }}^{2}$, \\ Greer Prettyman ${ }^{2}$, Theodore D. Satterthwaite ${ }^{2,5}$, Joseph W. Kable ${ }^{1}$ \\ ${ }^{1}$ Department of Psychology, University of Pennsylvania \\ ${ }^{2}$ Department of Psychiatry, Perelman School of Medicine \\ ${ }^{3}$ Department of Psychology, University of Minnesota \\ ${ }^{4}$ Department of Radiology, University of Pennsylvania \\ ${ }^{5}$ Penn-CHOP Lifespan Brain Institute
}

Corresponding author: Min Su Kang, Department of Psychology, University of Pennsylvania 3700 Hamilton Walk, Philadelphia, PA 19104. Email: minskang@sas.upenn.edu

Short title: Decision value signals and anhedonia

Key words: anhedonia, depression, bipolar disorder, schizophrenia, ventromedial prefrontal cortex, fMRI

Number of words in the abstract: $\quad 250$

Number of words in the main text: $\quad 3547$

Number of tables: $\quad 2$

Number of figures: $\quad 3$

Supplemental information: $\quad 1$ 


\begin{abstract}
Background: Anhedonia, or diminished pleasure, is a prominent symptom in mood and psychotic disorders. Anticipatory pleasure is particularly impaired in these conditions, which may be reflected in blunted activity in the fronto-striatal circuitry during evaluation of future rewards. This study examined the neural correlates of anhedonia during decision-making across mood and psychotic disorders.
\end{abstract}

Methods: Analyses included 81 adults with major depression $(\mathrm{N}=17)$, bipolar disorder (in depressed state, $\mathrm{N}=21)$, schizophrenia $(\mathrm{N}=23)$, or no history of psychopathology $(\mathrm{N}=20)$. Participants performed a delay discounting paradigm while functional imaging data were acquired at 3T. We examined the relationship between anhedonia and activity in two a priori regions of interest critical for valuation, the ventromedial prefrontal cortex (vmPFC) and ventral striatum. Anhedonia was measured using a semi-structured clinical interview; cognition, depression, and symptoms of psychosis were also evaluated.

Results: Discounting behavior did not differ as function of primary diagnosis or level of anhedonia $(F(3,77)=0.28, p=0.84 ; r=0.03, p=0.78)$. Value-related activity in the vmPFC was blunted in association with anhedonia $(\beta=-0.27 ; 95 \% \mathrm{CI},-0.48$ to $-0.06 ; p=0.01)$. This relationship remained significant while controlling for primary diagnosis, behavioral performance, cognitive functioning, smoking, depression severity, and both positive and negative symptoms of schizophrenia.

Conclusions: Hypofunction in the vmPFC during decision-making about future rewards is specifically linked to anhedonia, rather than a general feature of psychopathology. These findings help elucidate the pathophysiological underpinnings of anhedonia across mood and psychotic disorders and inform the development of novel treatment approaches. 


\section{Introduction}

Anhedonia, or diminished pleasure, is a prominent feature of many neuropsychiatric disorders. It is classified in the Diagnostic Statistical Manual (DSM) as one of the two core symptoms of a major depressive episode, which is a diagnostic requirement for major depressive disorder (MDD) and bipolar disorder (BD). Anhedonia is also a common negative symptom of schizophrenia (SCZ), suggesting a link between two seemingly distinct categories of psychiatric disorders (1). In both mood and psychotic disorders, anhedonia is difficult to treat and has been associated with suicidal ideation $(2,3)$, cognitive dysfunction $(4,5)$, and poor clinical prognosis (6). Although several theoretical papers have proposed examining the pathophysiology of anhedonia across mood and psychotic disorders (7-11), only recently have neuroimaging studies investigated anhedonia from a transdiagnostic perspective (12-17).

Across disorders, anhedonia has been linked to deficits in the brain's reward system, including the ventromedial prefrontal cortex (vmPFC) and ventral striatum (VS). Studies to date have examined anhedonia in relation to altered responses to either positive stimuli (18-20) or conditioned cues for positive outcomes (21-25). However, accumulating evidence suggests that anhedonia in these disorders is more prominent with respect to prospective anticipation rather than consumption (26). That is, anhedonia involves not only how individuals experience rewards or respond to reward cues, but specifically impacts how they evaluate potential rewards and decide which ones to pursue. This aligns with the distinction in decision neuroscience between experienced value, a signal at the time a reward or conditioned cue is experienced, and decision value, a signal at the time of choice (27). In the same way that anhedonia has been linked to reduced neural signals of experienced value (18-25), it might also be associated — and perhaps even more strongly — with dampened neural signals of decision value. However, the 
relationship between anhedonia and neural signals related to decision value has only been sparsely explored (16,28-30).

Delay discounting is a decision-making task that robustly elicits neural correlates of decision value throughout the valuation system - including the vmPFC, VS, and posterior cingulate cortex (PCC) $(31,32)$. In these tasks, individuals choose between a smaller proximal reward and a larger reward in the future (33). People tend to devalue, or discount, future rewards compared to more proximal ones. This tendency is captured by the discounting rate, $k$, which varies widely across individuals, with larger values indicating greater discounting (i.e., "impatient" or "temporally myopic"). Because delay discounting tasks specifically engage the ability to construct the value of future rewards (i.e., no rewards are actually delivered during the task), greater anhedonia may be associated with reduced neural representation of decision values for future rewards. Moreover, the regions where activity is correlated with decision value during these tasks (such as the vmPFC, VS, and PCC) $(31,32)$ have also been found to exhibit abnormalities in mood and psychotic disorders (34-36). To date, neuroimaging investigations of delay discounting in these conditions have been largely limited to case-control comparisons that focus on a single disorder $(37,38)$. Therefore, it remains an open question whether anhedonia across disorders is associated with dysregulation of decision value signals during prospective decision-making. Moving beyond case-control comparisons to a dimensional framework could reveal a common circuit-level mechanism for anhedonia across disorders.

The present study aimed to examine neural responses to decision values during delay discounting across MDD, BD, and SCZ, with the goal of further elucidating transdiagnostic abnormalities associated with anhedonia. We hypothesized that anhedonia would be associated with dampened decision value signals in the vmPFC and VS across all three clinical groups. 


\section{Methods and Materials}

\section{Participants}

Ninety-one participants who met clinical eligibility were recruited from a larger study $(35,39)$. Primary diagnosis of MDD, BD, or SCZ was ascertained using the Structured Clinical Interview for DSM-IV Axis I Disorders (SCID-IV) (40), and all participants in the MDD and BD group were in a depressive episode at the time of the scan to minimize any variance due to manic symptoms. For BD, both type I and II were included in the study, with three participants meeting the diagnostic criteria for type II. Healthy control participants were excluded if they met criteria for any Axis I psychiatric disorder. Given the association between substance use and delay discounting, participants with a history of pathological gambling, substance abuse or dependence in the past six months (with the exception of nicotine), or a positive urine drug screen on the day of the study were excluded. Given the evidence of elevated discount rates in cigarette smokers, coupled with higher prevalence of smoking in SCZ, all groups were matched on smoking status $(41,42)$. Of the 91 adults who met clinical eligibility, 4 were excluded from the analyses due to excessive head motion during the scan, and 6 due to idiosyncratic responses on the task (See Quality control analysis). Therefore, our final sample consisted of 81 participants. All study procedures were approved by the University of Pennsylvania's Institutional Review Board, and all participants provided written informed consent.

\section{Clinical and cognitive measures}

The Clinical Assessment Interview for Negative Symptoms - Beta (CAINS) was used as the primary measure of anhedonia (43). The CAINS assesses distinct domains of social, recreational, and vocational pleasure with a primary focus on subjective anhedonia, and therefore is less susceptible to environmental or external constraints than other existing scales $(35,44)$. 
Given the two-factor structure of the CAINS (motivation and pleasure, expression), we calculated an aggregate motivation and pleasure (CAINS MAP) score by taking the mean of all relevant items. Of the 81 participants included in the analysis, 77 were also administered the Calgary Depression Scale for Schizophrenia (CDSS) (45), the Scale for the Assessment of Positive Symptoms (SAPS) (46), and the Scale for the Assessment of Negative Symptoms (SANS) (47). For all clinical measures, higher scores indicate increasing levels of severity. Additionally, given prior reports associating DD and executive functioning (48-50), cognition was assessed using a subset of tasks from the Penn Computerized Neurocognitive Battery (CNB) (51) (see Computerized Neurocognitive Battery in the Supplement). An aggregate cognitive functioning score was calculated by taking the mean of standardized accuracy scores (z-scores) on individual tasks.

\section{Delay discounting task}

Delay discounting was assessed with an intertemporal choice task (Figure 1A) (32). The task consisted of 200 choices (4 runs of 50 trials) between two options: $\$ 20$ now and $\$ X$ in $Y$ days, in which $\mathrm{X}$ ranged from $\$ 20.50$ to $\$ 50$ and $\mathrm{Y}$ ranged from 1 to 178 days. Some versions of this task vary the amount of both immediate and delayed options (42), but keeping the immediate reward constant allows us to attribute variability in brain activity to changes in decision value of the delayed reward $(31,32)$. For each trial, participants had $4 \mathrm{~s}$ to make a response by pressing the right or left button, and the locations of now and delayed options were pseudorandomized across trials. Trials in which the participant did not make a choice in $4 \mathrm{~s}$ were coded as missing. Each trial was followed by a jittered inter-trial interval (ITI) that ranged from 2 to $20 \mathrm{~s}$.

Participants were informed that one of the trials would be randomly selected and realized at the end of the experiment; payment was provided on a debit card, available immediately or delayed 
according to the participant's choice on the randomly selected trial. EPrime (https://pstnet.com)

2.0 was used for task presentation.

\section{Parameter estimation}

Individual discount curves were fitted using a hyperbolic function (52-56), which assumes that the decision value (DV) of the delayed reward is:

$$
D V=\frac{A}{1+k D}
$$

where $A$ is the amount of the reward, $D$ is the delay to receiving the reward, and $k$ is the subjectspecific free parameter for their discount rate. Participants' individual choice data was fit with the following logistic function using maximum likelihood estimation with function minimization routines in MATLAB:

$$
\begin{gathered}
P_{\text {delayed }}=\frac{1}{\left.1+e^{-\sigma(D V \text { delayed }}-D V_{\text {immediate }}\right)} \\
P_{\text {immediate }}=1-P_{\text {delayed }}
\end{gathered}
$$

where $\sigma$ is the scaling parameter in the logistic function. Because $k$ was not normally distributed (Shapiro-Wilk's $W=0.69, p<.001$ ), individual $k$ was transformed using $\log _{10}$.

\section{Quality control analysis}

Runs that were missing more than $10 \%$ of the trials ( 5 out of 50 trials per run) were excluded from the analyses, in addition to those with excessive head motion for fMRI data processing (see Image processing). Four participants were excluded because there were fewer than two runs of usable data, due to excessive head motion or missing trials. Additionally, Tjur's coefficient of discrimination (Tjur's $D$ ) was used to assess the logistic model fit, and participants with Tjur's $D<0.20$ were excluded. One participant was excluded due to low Tjur's $D$. Lastly, participants who chose a single option (either the immediate or delayed reward) more than $99 \%$ of the task were excluded. Four participants were excluded because they only chose the 
immediate reward, and one participant was excluded because they only chose the delayed option across all trials. Therefore, our imaging and behavioral quality control analyses excluded 4 and 6 participants, respectively. For the subjects included for analyses $(\mathrm{N}=81)$, the percentage of choosing $\$ 20$ now ranged from $2.5 \%$ to $98.5 \%(M=58.99, S D=26.66)$.

\section{fMRI acquisition}

All images were acquired using a Siemens Tim Trio 3T and a 32-channel head coil. For functional images, $3 \mathrm{~mm}$ interleaved axial slices were acquired with echo-planar T2* weighting (repetition time $[\mathrm{TR}]=3000 \mathrm{~ms}$, echo time $[\mathrm{TE}]=30 \mathrm{~ms}$, flip angle $=90^{\circ}$, field of view $[\mathrm{FOV}]$ $=192 \times 192 \mathrm{~mm}$, matrix $=64 \times 64$, slice thickness $=3 \mathrm{~mm}$ ). Slice orientation was $-30^{\circ}$ from the anterior commissure-posterior commissure $(\mathrm{ACPC})$ plane to minimize signal drop out in the orbitofrontal cortex. Each run consisted of 168 images, and the first 6 volumes $(18 \mathrm{~s})$ of each scan were discarded to compensate for the T1 saturation effects. High-resolution T1-weighted MPRAGE anatomical images were acquired for spatial registration to a standard coordinate system (slice thickness $=1 \mathrm{~mm}, \mathrm{TR}=1810 \mathrm{~ms}, \mathrm{TE}=3.51 \mathrm{~ms}$, inversion time $[\mathrm{TI}]=1100 \mathrm{~ms}$, flip angle $=9^{\circ}, \mathrm{FOV}=1192 \times 256 \mathrm{~mm}$, matrix $=256 \times 192,160$ slices $)$. Additionally, a B0 field map was acquired for application of distortion correction procedures, using a double-echo gradient recall echo $(\mathrm{GRE})$ sequence $(\mathrm{TR}=1000 \mathrm{~ms}$, TE1 $2.69 \mathrm{~ms}$, TE2 $5.27 \mathrm{~ms}$, flip angle $=$ $60^{\circ}, \mathrm{FOV}=240 \mathrm{~mm}$, slice thickness $\left.=4 \mathrm{~mm}\right)$.

\section{Image processing}

Image processing and statistical analyses were performed using FSL 5.0.9

(http://www.fmrib.ox.ac.uk/fsl). All volumes were corrected for differences in slice acquisition using Fourier-space time-series phase-shifting and corrected for small head movements using MCFLIRT (57). Runs with mean relative displacement (MRD) greater than $0.30 \mathrm{~mm}$ were 
excluded. Data were smoothed using a Gaussian kernel of FWHM $6.0 \mathrm{~mm}$ and filtered in the temporal domain using a nonlinear high-pass filter (Gaussian-weighted least-squares straight line fitting with sigma $=50.0 \mathrm{~s}$ ). To account for anatomical differences across subjects and to allow for statistical inference at the group level, functional images were registered to the anatomical image and spatially normalized to standard MNI space (MNI152, T1 2mm) using linear registration with FMRIB's Linear Image Registration Tool (FLIRT) and further refined using FNIRT nonlinear registration (57-59).

\section{fMRI analysis}

Using FSL FMRI Expert Analysis Tool Version 6.0, we fit a general linear model (GLM) that estimated (1) averaged activity for all decisions versus rest (trial regressor) and (2) activity that was correlated across trials with the decision value of the delayed option (DV regressor, calculated using Equation 1 above with the subject-specific $k$ ). The first two trials of each run were deleted prior to analysis. All other events were modeled with a fixed duration of $4 \mathrm{~s}$ following the stimulus presentation, and convolved with a canonical double-gamma HRF. Temporal derivatives of these two regressors, as well as the six motion parameters, were included as covariates of no interest. Missed trials, in which the participant failed to make a response in $4 \mathrm{~s}$, were modeled separately.

Subsequently, all eligible runs from each participant were combined using a fixed effect model. Group-level analyses were performed using FMRIB Local Analysis of Mixed Effects module (60). For region-of-interest (ROI) analyses, we used the vmPFC and VS clusters reported in a meta-analysis examining the neural correlates of decision value (See Figure 6A in Bartra et al. (2013) (61)). To test for any differences in activations across groups, an F-test was performed. To test for the main effect of anhedonia across the whole brain, individual MAP scores were 
demeaned and included in the GLM as an explanatory variable. Thresholded $Z$ statistic images were prepared by using a threshold of $Z>3.1$ and a corrected extent threshold of $p<0.05$, familywise error-corrected using Gaussian Random Fields Theory (62). In all multisubject statistics, outliers were de-weighted using mixture modeling (63).

\section{Statistical analyses}

Parameter estimation and quality control analyses were performed in MATLAB R2016b (Mathworks). All imaging analyses were performed in FSL 5.0.9. All statistical analyses were performed in R 3.5.2 (CRAN). All pairwise t-tests were corrected for multiple comparisons using Holm's method (64). For confound analysis, DV-related activity in the ROI was regressed on each covariate separately to identify significant covariates. Multiple linear regressions were performed to statistically control for diagnosis and other covariates.

\section{Results}

\section{Participants}

Demographic and clinical characteristics are available in Table 1. All three clinical groups scored higher on the CAINS MAP than healthy participants $\left(t_{\mathrm{MDD}>\mathrm{HC}}=5.16, t_{\mathrm{BD}>\mathrm{HC}}=\right.$ $6.34, t_{\mathrm{SCZ}>\mathrm{HC}}=3.80$, all $p$ 's $\left.<0.01\right)$, but did not differ from one another $(F(2,58)=2.68, p=$ 0.08). Depressive and negative symptoms were also higher in all three clinical groups (all $p$ 's $<$ $0.05)$, while positive symptoms were higher only in $\operatorname{SCZ}(t=4.87$, all $p<0.01)$. SCZ also had significantly worse overall cognition than healthy participants $(t=3.35, p=0.007)$. Across the entire sample, anhedonia was significantly correlated with cognitive functioning $(r=-0.34)$, smoking $(r=0.27)$, depressive symptoms $(r=0.54)$, and negative symptoms $(r=0.51)$ (all $p$ 's $<$ 0.05, Supplemental Table S1). 


\section{Behavioral results}

Individual discount rates (raw $k$ values) ranged from 0.0006 (most patient) to 0.27 (least patient), with a geometric mean of 0.017 . The $\log (k)$ did not differ significantly across groups $(F(3,77)=0.28, p=0.84)($ Figure $1 \mathrm{~B})$ or by smoking status $(t=0.81, p=0.42)$, and was not correlated with anhedonia $(r=0.034, p=0.78)$ (Figure 1C). We assessed two measures of model fit, Tjur's $D$ (range $=0.22-0.94$, mean $[\mathrm{SD}]=0.64[0.17])$ and the percentage of choices predicted $($ range $=53.6 \%-98.7 \%$, mean $[\mathrm{SD}]=88.5[7.75])$; neither significantly differed across groups (Tjur's $D: F(3,77)=2.38, p=0.08 ; \%$ correct prediction: $F(3,77)=2.09, p=0.11)$.

\section{Anhedonia and the value signals}

Consistent with previous reports $(31,32)$, decision value was correlated with activity in widespread regions, including the vmPFC, VS, and PCC, across all participants (Supplemental Figure S1). For ROI analyses, we defined the vmPFC and VS based on a meta-analysis of neural correlates of decision value during decision-making (Figure 2A, B) (61). An F-test revealed no significant group differences in DV-related activity in the $\operatorname{vmPFC}(F(3,77)=1.84, p=0.15)$ or $\operatorname{VS}(F(3,77)=1.92, p=0.13)($ Figure $2 \mathrm{C}, \mathrm{D})$. However, the DV-related activity in the vmPFC was inversely correlated with anhedonia, such that individuals with increasing levels of anhedonia exhibited weaker value signals in the vmPFC $(r=-0.27, p=0.01)$ (Figure 2E). Conversely, the relationship between anhedonia and DV-related activity was not significant in the VS $(r=-0.10, p=0.36)$ (Figure $2 \mathrm{~F})$.

\section{Specificity of anhedonia}

To ascertain the specificity of the effect of anhedonia on value-related activity in the vmPFC, we performed a series of sensitivity analyses to consider the following covariates: primary diagnosis (MDD, BD, and SCZ), performance on the cognitive battery (CNB), smoking, 
severity of depression (CDSS), positive and negative symptoms (SAPS, SANS), and behavioral performance $(\log (k)$ and Tjur's $D)$. Of these covariates, the diagnosis of SCZ, negative symptoms, and cognition were each individually associated with DV-related activity in the $\operatorname{vmPFC}(\beta(\mathrm{SE}), p$ for $\mathrm{SCZ}=-0.29(0.14), 0.04 ; \mathrm{SANS}=-0.22(0.11), 0.04 ; \mathrm{CNB}=0.27(0.10)$, 0.02). However, in multiple linear regressions that included diagnoses alone (Table 2, Model 2) or all potential confounds (Model 3), anhedonia remained a significant predictor of DV-related activity and the inclusion of these covariates did not reduce the size of its standardized coefficient. Excluding participants on any one class of medication also did not significantly change the effect of anhedonia (Supplemental Table S2).

\section{Exploratory whole-brain analyses}

Beyond our a priori ROIs, we conducted an exploratory analysis for the correlation between anhedonia and DV-related signal across the whole brain. We found that higher anhedonia scores were significantly associated with greater value signals in the left PCC $(Z>$ 3.1, $p<0.05$, FWE corrected) (Figure 3).

\section{Discussion}

The present study examined value-related brain activity during decision-making across mood and psychotic disorders, as a function of anhedonia. Our analyses revealed that valuerelated activity in the vmPFC was reduced with anhedonia, such that individuals with more severe anhedonia exhibited a blunted response to increasing values of the future reward in a prospective decision-making task. Moreover, anhedonia predicted decision value signals in the vmPFC above and beyond the effects of primary diagnosis, cognitive functioning, nicotine use, severity of depression, and positive and negative symptoms. These results demonstrate the 
specificity of the effects of anhedonia on vmPFC function in the context of evaluating future rewards. These results further suggest that the vmPFC may be an important therapeutic target for anhedonia and amotivation.

Prior studies investigating reward-related dysfunction in mood and psychotic disorders have often used general symptom severity (e.g., depressive or negative symptoms) or blunted neural activity as a proxy of anhedonia. Here we demonstrate specific links between anhedonia, as assessed by a validated clinical interview, and value-related neural activity in the context of decision-making. The present study is a novel addition to the existing literature that has primarily focused on responses to reward consumption (18-20) or reward-related cues (21-25). As evidence accumulates that anhedonia may manifest as impaired decision-making (26), it is important to understand not only the aspects of reward experience, but also how prospective reward is evaluated and translated into goal-directed action.

Prior studies relating anhedonia to neural responses to rewards or reward cues reported striatal hypoactivity, and often did not find a significant effect in the vmPFC (21-25). In contrast, we found that anhedonia was inversely correlated with value-related activity in the vmPFC, while in the VS this inverse relationship was a non-significant trend. This discrepancy may be partly due to the focus on experienced versus decision value signals. Meta-analyses report stronger experienced value-related activity in the VS, and stronger decision value-related activity in the vmPFC, though both kinds of signals are present in both regions $(61,65)$. Additionally, VS activity can partly be driven by feedback and prediction errors (66), and no reward was delivered during our task.

Beyond these a priori regions of interest, individuals with anhedonia recruited the PCC to a greater extent in encoding the decision value of future rewards. Though exploratory, this 
finding is broadly consistent with a prior study that found greater PCC activation in individuals with SCZ during the DD task (37). One speculation is that this increased signal of decision value in the PCC might reflect compensation for weaker decision value signals in the vmPFC in anhedonic individuals. Regardless of the interpretation, this result provides further evidence that the representation of decision values is altered in anhedonia.

In this study, neither diagnosis nor anhedonia was associated with discounting rate. Prior behavioral studies have reported elevated discount rates in SCZ (49,67-70), although results are mixed in mood disorders $(68,70-75)$. Although not statistically significant in our sample, we observed a trend in individuals with SCZ to discount more than others. The absence of significant behavioral differences in our sample aids interpretation of the imaging findings, as the observed functional differences are not secondary to behavioral differences on the task. Specifically, differences in performance in clinical groups can confound the interpretation of neural differences, a limitation that is often overcome by matching for behavioral performance (37,76-78). Another potential behavioral confound is that the estimates of decision value (i.e., the discounting model fits) might be less accurate in anhedonic participants. However, we can rule out this confound here, because anhedonia predicted vmPFC activity after controlling for model fit.

Our study has several limitations. First, the MAP subscale of the CAINS constitutes a single factor not suited for distinguishing anticipatory from consummatory anhedonia, and we might expect vmPFC function to be more strongly related to the anticipatory aspects of anhedonia. However, both domains of anhedonia are elevated in these disorders and the two domains tend to be highly correlated on self-reports (79). Second, we did not evaluate whether vmPFC hypofunction in anhedonia is a general feature of decision-making, or rather specific to 
delay discounting. Despite these limitations, these findings demonstrate that perturbed value signals in this region during the evaluation of future rewards correlated with the severity of anhedonia, over and above the effects of clinical diagnosis, cognitive functioning, or severity of depression as well as positive and negative symptoms. Demonstrating such symptom-specific alterations across diagnoses helps elucidate the pathophysiological underpinnings of anhedonia and can inform future treatment development.

\section{Acknowledgements}

This research was supported in part by the National Institute of Mental Health (R01MH113565 and R01MH101111 to DHW; R01MH113550, R01MH107703, and K23MH098130 to TDS) and University of Pennsylvania (Penn Translational Neuroscience Center [to DHW, TDS, and JWK], Penn-CHOP Lifespan Brain Institute [to TDS]). All funding agencies had no role in the design and conduct of the study; collection, management, analysis, and interpretation of the data; preparation, review, or approval of the manuscript; and decision to submit the manuscript for publication. A subset of analyses reported here were presented (by MSK) at the 2019 annual meeting of the Society for NeuroEconomics.

\section{Disclosures}

All authors report no biomedical financial interests or potential conflicts of interest. 


\section{References}

1. Bedwell JS, Gooding DC, Chan CC, Trachik BJ. Anhedonia in the age of RDoC. Schizophr Res. 2014 Dec 1;160(1):226-7.

2. Ballard ED, Wills K, Lally N, Richards EM, Luckenbaugh DA, Walls T, et al. Anhedonia as a clinical correlate of suicidal thoughts in clinical ketamine trials. J Affect Disord. 2017 Aug 15;218:195-200.

3. Ducasse D, Loas G, Dassa D, Gramaglia C, Zeppegno P, Guillaume S, et al. Anhedonia is associated with suicidal ideation independently of depression: A meta-analysis. Depress Anxiety. 2018;35(5):382-92.

4. Franke P, Maier W, Hardt J, Hain C. Cognitive functioning and anhedonia in subjects at risk for schizophrenia. Schizophr Res. 1993 Jun 1;10(1):77-84.

5. McIntyre RS, Woldeyohannes HO, Soczynska JK, Maruschak NA, Wium-Andersen IK, Vinberg M, et al. Anhedonia and cognitive function in adults with MDD: results from the International Mood Disorders Collaborative Project. CNS Spectr. 2016 Oct;21(5):362-6.

6. McMakin DL, Olino TM, Porta G, Dietz LJ, Emslie G, Clarke G, et al. Anhedonia Predicts Poorer Recovery Among Youth With Selective Serotonin Reuptake Inhibitor TreatmentResistant Depression. J Am Acad Child Adolesc Psychiatry. 2012 Apr 1;51(4):404-11.

7. Lambert C, Da Silva S, Ceniti AK, Rizvi SJ, Foussias G, Kennedy SH. Anhedonia in depression and schizophrenia: A transdiagnostic challenge. CNS Neurosci Ther. 2018;24:615-23.

8. Whitton A, Treadway M, Pizzagalli D. Reward processing dysfunction in major depression, bipolar disorder and schizophrenia. Curr Opin Psychiatry. 2015 Jan 1;28(1):7-12.

9. Winograd-Gurvich C, Fitzgerald PB, Georgiou-Karistianis N, Bradshaw JL, White OB. Negative symptoms: A review of schizophrenia, melancholic depression and Parkinson's disease. Brain Res Bull. 2006 Oct 16;70(4):312-21.

10. Barch DM, Pagliaccio D, Luking K. Mechanisms Underlying Motivational Deficits in Psychopathology: Similarities and Differences in Depression and Schizophrenia. In: Simpson EH, Balsam PD, editors. Behavioral Neuroscience of Motivation [Internet]. Cham: Springer International Publishing; 2016 [cited 2019 Aug 14]. p. 411-49. (Current Topics in Behavioral Neurosciences). Available from: https://doi.org/10.1007/7854_2015_376

11. Husain M, Roiser JP. Neuroscience of apathy and anhedonia: a transdiagnostic approach. Nat Rev Neurosci. 2018 Aug;19(8):470-84.

12. Sharma A, Wolf DH, Ciric R, Kable JW, Moore TM, Vandekar SN, et al. ConnectomeWide Analysis Reveals Common Dimensional Reward Deficits Across Mood and Psychotic Disorders. Am J Psychiatry. 2017 Jul 1;174(7):657-66. 
13. Schilbach L, Hoffstaedter F, Müller V, Cieslik EC, Goya-Maldonado R, Trost S, et al. Transdiagnostic commonalities and differences in resting state functional connectivity of the default mode network in schizophrenia and major depression. NeuroImage Clin. 2016 Jan 1;10:326-35.

14. Segarra N, Metastasio A, Ziauddeen H, Spencer J, Reinders NR, Dudas RB, et al. Abnormal Frontostriatal Activity During Unexpected Reward Receipt in Depression and Schizophrenia: Relationship to Anhedonia. Neuropsychopharmacology. 2016 Jul;41(8):2001-10.

15. Arrondo G, Segarra N, Metastasio A, Ziauddeen H, Spencer J, Reinders NR, et al. Reduction in ventral striatal activity when anticipating a reward in depression and schizophrenia: a replicated cross-diagnostic finding. Front Psychol [Internet]. 2015 [cited 2019 Jul 20];6. Available from:

https://www.frontiersin.org/articles/10.3389/fpsyg.2015.01280/full

16. Gradin VB, Kumar P, Waiter G, Ahearn T, Stickle C, Milders M, et al. Expected value and prediction error abnormalities in depression and schizophrenia. Brain J Neurol. 2011 Jun;134(Pt 6):1751-64.

17. Park IH, Lee BC, Kim J-J, Kim JI, Koo M-S. Effort-Based Reinforcement Processing and Functional Connectivity Underlying Amotivation in Medicated Patients with Depression and Schizophrenia. J Neurosci. 2017 Apr 19;37(16):4370-80.

18. Keedwell PA, Andrew C, Williams SCR, Brammer MJ, Phillips ML. The neural correlates of anhedonia in major depressive disorder. Biol Psychiatry. 2005 Dec 1;58(11):843-53.

19. Harvey P-O, Pruessner J, Czechowska Y, Lepage M. Individual differences in trait anhedonia: a structural and functional magnetic resonance imaging study in non-clinical subjects. Mol Psychiatry. 2007 Aug;12(8):703, 767-75.

20. Epstein J, Pan H, Kocsis JH, Yang Y, Butler T, Chusid J, et al. Lack of ventral striatal response to positive stimuli in depressed versus normal subjects. Am J Psychiatry. 2006 Oct;163(10):1784-90.

21. Wacker J, Dillon DG, Pizzagalli DA. The role of the nucleus accumbens and rostral anterior cingulate cortex in anhedonia: integration of resting EEG, fMRI, and volumetric techniques. NeuroImage. 2009 May 15;46(1):327-37.

22. Simon JJ, Biller A, Walther S, Roesch-Ely D, Stippich C, Weisbrod M, et al. Neural correlates of reward processing in schizophrenia - Relationship to apathy and depression. Schizophr Res. 2010 May 1;118(1):154-61.

23. Stoy M, Schlagenhauf F, Sterzer P, Bermpohl F, Hägele C, Suchotzki K, et al. Hyporeactivity of ventral striatum towards incentive stimuli in unmedicated depressed patients normalizes after treatment with escitalopram. J Psychopharmacol (Oxf). 2012 May 1;26(5):677-88. 
24. Juckel G, Schlagenhauf F, Koslowski M, Filonov D, Wüstenberg T, Villringer A, et al. Dysfunction of ventral striatal reward prediction in schizophrenic patients treated with typical, not atypical, neuroleptics. Psychopharmacology (Berl). 2006 Aug;187(2):222-8.

25. Juckel G, Schlagenhauf F, Koslowski M, Wüstenberg T, Villringer A, Knutson B, et al. Dysfunction of ventral striatal reward prediction in schizophrenia. NeuroImage. 2006 Jan 15;29(2):409-16.

26. Treadway MT, Zald DH. Reconsidering anhedonia in depression: Lessons from translational neuroscience. Neurosci Biobehav Rev. 2011 Jan 1;35(3):537-55.

27. Platt ML, Plassmann H. Chapter 13 - Multistage Valuation Signals and Common Neural Currencies. In: Glimcher PW, Fehr E, editors. Neuroeconomics (Second Edition) [Internet]. San Diego: Academic Press; 2014 [cited 2019 Jul 22]. p. 237-58. Available from: http://www.sciencedirect.com/science/article/pii/B9780124160088000139

28. Huang J, Yang X, Lan Y, Zhu C, Liu X, Wang Y, et al. Neural substrates of the impaired effort expenditure decision making in schizophrenia. Neuropsychology. 20160407;30(6):685.

29. Yang X, Huang J, Lan Y, Zhu C, Liu X, Wang Y, et al. Diminished caudate and superior temporal gyrus responses to effort-based decision making in patients with first-episode major depressive disorder. Prog Neuropsychopharmacol Biol Psychiatry. 2016 Jan 4;64:529.

30. Dowd EC, Frank MJ, Collins A, Gold JM, Barch DM. Probabilistic Reinforcement Learning in Patients With Schizophrenia: Relationships to Anhedonia and Avolition. Biol Psychiatry Cogn Neurosci Neuroimaging. 2016 Sep;1(5):460-73.

31. Kable JW, Glimcher PW. The neural correlates of subjective value during intertemporal choice. Nat Neurosci. 2007 Dec;10(12):1625-33.

32. Kable JW, Glimcher PW. An "as soon as possible" effect in human intertemporal decision making: behavioral evidence and neural mechanisms. J Neurophysiol. 2010 May;103(5):2513-31.

33. Kirby KN, MarakoviĆ NN. Delay-discounting probabilistic rewards: Rates decrease as amounts increase. Psychon Bull Rev. 1996 Mar 1;3(1):100-4.

34. Zhang B, Lin P, Shi H, Öngür D, Auerbach RP, Wang X, et al. Mapping anhedonia-specific dysfunction in a transdiagnostic approach: an ALE meta-analysis. Brain Imaging Behav. 2016;10(3):920-39.

35. Wolf DH, Satterthwaite TD, Kantrowitz JJ, Katchmar N, Vandekar L, Elliott MA, et al. Amotivation in Schizophrenia: Integrated Assessment With Behavioral, Clinical, and Imaging Measures. Schizophr Bull. 2014 Nov 1;40(6):1328-37. 
36. Satterthwaite TD, Kable JW, Vandekar L, Katchmar N, Bassett DS, Baldassano CF, et al. Common and Dissociable Dysfunction of the Reward System in Bipolar and Unipolar Depression. Neuropsychopharmacol Off Publ Am Coll Neuropsychopharmacol. 2015 Aug;40(9):2258-68.

37. Avsar KB, Weller RE, Cox JE, Reid MA, White DM, Lahti AC. An fMRI investigation of delay discounting in patients with schizophrenia. Brain Behav. 2013 Jul;3(4):384-401.

38. Vanyukov PM, Szanto K, Hallquist MN, Siegle GJ, Reynolds CF, Forman SD, et al. Paralimbic and lateral prefrontal encoding of reward value during intertemporal choice in attempted suicide. Psychol Med. 2016 Jan;46(2):381-91.

39. Hershenberg R, Satterthwaite TD, Daldal A, Katchmar N, Moore TM, Kable JW, et al. Diminished effort on a progressive ratio task in both unipolar and bipolar depression. J Affect Disord. 2016 May 15;196:97-100.

40. First MB, Gibbon M. The Structured Clinical Interview for DSM-IV Axis I Disorders (SCID-I) and the Structured Clinical Interview for DSM-IV Axis II Disorders (SCID-II). In: Comprehensive handbook of psychological assessment, Vol 2: Personality assessment. Hoboken, NJ, US: John Wiley \& Sons Inc; 2004. p. 134-43.

41. Wing VC, Moss TG, Rabin RA, George TP. Effects of cigarette smoking status on delay discounting in schizophrenia and healthy controls. Addict Behav. 2012;37(1):67-72.

42. Yu LQ, Lee S, Katchmar N, Satterthwaite TD, Kable JW, Wolf DH. Steeper discounting of delayed rewards in schizophrenia but not first-degree Relatives. Psychiatry Res. 2017 Jun;252:303-9.

43. Kring AM, Gur RE, Blanchard JJ, Horan WP, Reise SP. The Clinical Assessment Interview for Negative Symptoms (CAINS): Final Development and Validation. Am J Psychiatry. 2013 Feb 1;170(2):165-72.

44. Strauss GP, Gold JM. A Psychometric Comparison of the Clinical Assessment Interview for Negative Symptoms and the Brief Negative Symptom Scale. Schizophr Bull. 2016 Nov 1;42(6):1384-94.

45. Addington D, Addington J, Schissel B. A depression rating scale for schizophrenics. Schizophr Res. 1990 Aug;3(4):247-51.

46. Andreasen NC. Scale for the Assessment of Positive Symptoms (SAPS). Br J Psychiatry. 1989;155(Suppl 7):53-8.

47. Andreasen NC. The Scale for the Assessment of Negative Symptoms (SANS): Conceptual and Theoretical Foundations. Br J Psychiatry. 1989 Nov;155(S7):49-52.

48. Bickel WK, Yi R, Landes RD, Hill PF, Baxter C. Remember the Future: Working Memory Training Decreases Delay Discounting Among Stimulant Addicts. Biol Psychiatry. 2011 Feb 1;69(3):260-5. 
49. Heerey EA, Matveeva TM, Gold JM. Imagining the future: degraded representations of future rewards and events in schizophrenia. J Abnorm Psychol. 2011 May;120(2):483-9.

50. Hinson JM, Jameson TL, Whitney P. Impulsive decision making and working memory. J Exp Psychol Learn Mem Cogn. 2003 Mar;29(2):298-306.

51. Moore TM, Reise SP, Gur RE, Hakonarson H, Gur RC. Psychometric properties of the Penn Computerized Neurocognitive Battery. Neuropsychology. 2015;29(2):235-46.

52. Kirby KN, Herrnstein RJ. Preference Reversals Due to Myopic Discounting of Delayed Reward. Psychol Sci. 1995 Mar;6(2):83-9.

53. Lempert KM, Pizzagalli DA. Delay Discounting and Future-directed Thinking in Anhedonic Individuals. J Behav Ther Exp Psychiatry. 2010 Sep;41(3):258-64.

54. Myerson J, Green L. Discounting of Delayed Rewards: Models of Individual Choice. J Exp Anal Behav. 1995;64(3):263-76.

55. Rachlin H, Raineri A, Cross D. Subjective probability and delay. J Exp Anal Behav. 1991 Mar;55(2):233-44.

56. Richards JB, Zhang L, Mitchell SH, Wit H de. Delay or Probability Discounting in a Model of Impulsive Behavior: Effect of Alcohol. J Exp Anal Behav. 1999;71(2):121-43.

57. Jenkinson M, Bannister P, Brady M, Smith S. Improved Optimization for the Robust and Accurate Linear Registration and Motion Correction of Brain Images. NeuroImage. 2002 Oct 1;17(2):825-41.

58. Andersson JL, Jenkinson M, Smith S. Non-linear registration, aka spatial normalisation FMRIB Technial Report TR07JA2. FMRIB Anal Group Univ Oxf. 2007;

59. Jenkinson M, Smith S. A global optimisation method for robust affine registration of brain images. Med Image Anal. 2001 Jun;5(2):143-56.

60. Beckmann CF, Jenkinson M, Smith SM. General multilevel linear modeling for group analysis in FMRI. NeuroImage. 2003 Oct;20(2):1052-63.

61. Bartra O, McGuire JT, Kable JW. The valuation system: A coordinate-based meta-analysis of BOLD fMRI experiments examining neural correlates of subjective value. NeuroImage. 2013 Aug 1;76:412-27.

62. Poline JB, Worsley KJ, Evans AC, Friston KJ. Combining spatial extent and peak intensity to test for activations in functional imaging. NeuroImage. 1997 Feb;5(2):83-96.

63. Woolrich M. Robust group analysis using outlier inference. NeuroImage. 2008 Jun;41(2):286-301. 
64. Holm S. A Simple Sequentially Rejective Multiple Test Procedure. Scand J Stat. 1979;6(2):65-70.

65. Oldham S, Murawski C, Fornito A, Youssef G, Yücel M, Lorenzetti V. The anticipation and outcome phases of reward and loss processing: A neuroimaging meta-analysis of the monetary incentive delay task. Hum Brain Mapp. 2018;39(8):3398-418.

66. Pessiglione M, Seymour B, Flandin G, Dolan RJ, Frith CD. Dopamine-dependent prediction errors underpin reward-seeking behaviour in humans. Nature. 2006 Aug;442(7106):1042-5.

67. Heerey EA, Robinson BM, McMahon RP, Gold JM. Delay discounting in schizophrenia. Cognit Neuropsychiatry. 2007 May;12(3):213-21.

68. Ahn W-Y, Rass O, Fridberg DJ, Bishara AJ, Forsyth JK, Breier A, et al. Temporal discounting of rewards in patients with bipolar disorder and schizophrenia. J Abnorm Psychol. 2011;120(4):911-21.

69. Weller RE, Avsar KB, Cox JE, Reid MA, White DM, Lahti AC. Delay discounting and task performance consistency in patients with schizophrenia. Psychiatry Res. 2014 Feb 28;215(2):286-93.

70. Brown HE, Hart KL, Snapper LA, Roffman JL, Perlis RH. Impairment in delay discounting in schizophrenia and schizoaffective disorder but not primary mood disorders. Npj Schizophr. 2018 May 28;4(1):9.

71. Mason L, O’Sullivan N, Blackburn M, Bentall R, El-Deredy W. I want it now! Neural correlates of hypersensitivity to immediate reward in hypomania. Biol Psychiatry. 2012 Mar 15;71(6):530-7.

72. Urošević S, Youngstrom EA, Collins P, Jensen JB, Luciana M. Associations of Age with Reward Delay Discounting and Response Inhibition in Adolescents with Bipolar Disorders. J Affect Disord. 2016 Jan 15;190:649-56.

73. Imhoff S, Harris M, Weiser J, Reynolds B. Delay discounting by depressed and nondepressed adolescent smokers and non-smokers. Drug Alcohol Depend. 2014 Feb 1;135:152-5.

74. Pulcu E, Trotter PD, Thomas EJ, McFarquhar M, Juhasz G, Sahakian BJ, et al. Temporal discounting in major depressive disorder. Psychol Med. 2014 Jul;44(9):1825-34.

75. Takahashi T, Oono H, Inoue T, Boku S, Kako Y, Kitaichi Y, et al. Depressive patients are more impulsive and inconsistent in intertemporal choice behavior for monetary gain and loss than healthy subjects--an analysis based on Tsallis' statistics. Neuro Endocrinol Lett. 2008 Jun;29(3):351-8. 
76. Lee J, Folley BS, Gore J, Park S. Origins of Spatial Working Memory Deficits in Schizophrenia: An Event-Related fMRI and Near-Infrared Spectroscopy Study. PLOS ONE. 2008 Mar 12;3(3):e1760.

77. Barch DM, Carter CS, Braver TS, Sabb FW, MacDonald A, Noll DC, et al. Selective Deficits in Prefrontal Cortex Function in Medication-Naive Patients With Schizophrenia. Arch Gen Psychiatry. 2001 Mar 1;58(3):280-8.

78. Cannon TD, Glahn DC, Kim J, Erp TGMV, Karlsgodt K, Cohen MS, et al. Dorsolateral Prefrontal Cortex Activity During Maintenance and Manipulation of Information in Working Memory in Patients With Schizophrenia. Arch Gen Psychiatry. 2005 Oct 1;62(10):1071-80.

79. Li Y, Mou X, Jiang W, Yang Z, Shen X, Jin Z, et al. A comparative study of anhedonia components between major depression and schizophrenia in Chinese populations. Ann Gen Psychiatry. 2015 Sep 3;14(1):24. 


\section{Table legends}

Table 1. Descriptive and group comparison statistics for sample characteristics.

Note: All values in $\mathrm{X}(\mathrm{Y})$ format are mean (standard deviation). $\mathrm{HC}=$ healthy control, $\mathrm{MDD}=$ major depressive disorder, $\mathrm{BD}=$ bipolar disorder, $\mathrm{SCZ}=$ schizophrenia, $\mathrm{CNB}=$ average $\mathrm{z}$-score on the Penn Computerized Neurocognitive Battery, $\log _{10}(k)=$ subject-specific parameter for discount rate, Tjur's $D=$ Tjur's coefficient of discrimination, $\%$ predicted $=$ percentage of correct model predictions of choice, CAINS MAP = motivation and pleasure, $\mathrm{CDSS}=$ Calgary Depression Scale for Schizophrenia, SAPS = Scale for the Assessment of Positive Symptoms, SANS $=$ Scale for the Assessment of Negative Symptoms.

$* p<.05$ for univariate ANOVA across the four groups.

a Three participants met the diagnostic criteria for bipolar disorder type II.

${ }^{\mathrm{b}}$ Data available on a subsample $(\mathrm{n}=77)$.

Table 2. Beta coefficients and standard errors from linear regression models (dependent variable $=$ beta coefficients for DV in the vmPFC).

Note: $\mathrm{CAINS} \mathrm{MAP}=$ motivation and pleasure, $\mathrm{MDD}=$ major depressive disorder, $\mathrm{BD}=$ bipolar disorder, $\mathrm{SCZ}=$ schizophrenia, $\mathrm{CNB}=$ average $\mathrm{z}$-score on the Penn Computerized Neurocognitive Battery, Smoke $=1$ for smoker, 0 for non-smoker, CDSS $=$ Calgary Depression Scale for Schizophrenia, SAPS = Scale for the Assessment of Positive Symptoms, SANS = Scale for the Assessment of Negative Symptoms, $\log _{10}(k)=$ subject-specific parameter for discount rate, Tjur's $D=$ Tjur's coefficient of discrimination 
$* p<.05$

\section{Figure legends}

Figure 1. (A) Delay discounting fMRI paradigm. Participants chose between two options: \$20 now and a larger reward at various delays. The chosen option was underlined for the remaining part of the trial duration to provide visual feedback of their choice. Each trial was followed by a jittered inter-trial interval (ITI) that ranged from 2 to $20 \mathrm{~s}$. (B) Discount rate, $\log (k)$, did not differ significantly by primary diagnosis $(F(3,77)=0.28, p=0.84)$. (C) Similarly, discount rate was not correlated with anhedonia $(r=0.034, p=0.78)$.

Note: $\log (\mathrm{k})=$ individual discount rate, $\mathrm{HC}=$ healthy control, $\mathrm{MDD}=$ major depressive disorder, $\mathrm{BD}=$ bipolar disorder, $\mathrm{SCZ}=$ schizophrenia, $\mathrm{CAINS} \mathrm{MAP}=$ Motivation and Pleasure subscale score of the CAINS.

Figure 2. (A, B) The functional masks for the vmPFC (blue) and VS (red) as reported in a metaanalysis by Bartra et al. (2013). No significant difference by primary diagnosis was found in the (C) vmPFC or (D) VS. (E) DV-related activity in the vmPFC was inversely correlated with anhedonia (CAINS MAP). (F) This correlation was not significant in the VS.

Note: $\mathrm{DV}=$ decision value of the delayed reward, $\mathrm{HC}=$ healthy control, $\mathrm{MDD}=$ major depressive disorder, $\mathrm{BD}=$ bipolar disorder, $\mathrm{SCZ}=$ schizophrenia, $\mathrm{CAINS} \mathrm{MAP}=$ Motivation and Pleasure subscale score of the CAINS. 
bioRxiv preprint doi: https://doi.org/10.1101/2020.12.01.407197; this version posted December 2, 2020. The copyright holder for this preprint

(which was not certified by peer review) is the author/funder, who has granted bioRxiv a license to display the preprint in perpetuity. It is made available under aCC-BY-ND 4.0 International license.

Figure 3. Exploratory whole-brain analysis of the correlation between DV-related activity and anhedonia. Higher scores on the CAINS MAP are associated with greater DV-related activity in the left PCC $(Z>3.1, p<0.05$, FWE corrected $)$. 
Table 1. Descriptive and group comparison statistics for sample characteristics

\begin{tabular}{|c|c|c|c|c|}
\hline & $\mathrm{HC}$ & MDD & $\mathrm{BD}^{\mathrm{a}}$ & SCZ \\
\hline $\mathrm{N}$ & 20 & 17 & 21 & 23 \\
\hline Age in years & $41.70(10.56)$ & $35.02(12.62)$ & $37.66(11.56)$ & $41.16(10.01)$ \\
\hline Sex: male & $35.00 \%$ & $47.06 \%$ & $66.67 \%$ & $39.13 \%$ \\
\hline \multicolumn{5}{|l|}{ Race } \\
\hline White & $55.00 \%$ & $58.82 \%$ & $66.67 \%$ & $30.43 \%$ \\
\hline African American & $45.00 \%$ & $29.41 \%$ & $28.57 \%$ & $60.86 \%$ \\
\hline Asian & $0 \%$ & $5.88 \%$ & $4.76 \%$ & $4.35 \%$ \\
\hline Mixed & $0 \%$ & $5.88 \%$ & $0 \%$ & $4.35 \%$ \\
\hline \multicolumn{5}{|l|}{ Ethnicity } \\
\hline Non Hispanic & $100 \%$ & $94.11 \%$ & $85.71 \%$ & $95.65 \%$ \\
\hline Hispanic & $0 \%$ & $5.88 \%$ & $14.29 \%$ & $4.35 \%$ \\
\hline Years of education & $15.00(2.20)$ & $14.82(2.58)$ & $15.48(2.25)$ & $13.70(1.82)$ \\
\hline \multicolumn{5}{|l|}{ Delay discounting task } \\
\hline $\log _{10}(k)$ & $-1.81(0.67)$ & $-1.81(0.43)$ & $-1.79(0.74)$ & $-1.67(0.44)$ \\
\hline Tjur's $D$ & $0.71(0.18)$ & $0.65(0.18)$ & $0.64(0.17)$ & $0.57(0.14)$ \\
\hline$\%$ predicted & $90.98(6.12)$ & $85.53(8.10)$ & $89.78(9.73)$ & $87.49(5.98)$ \\
\hline \multicolumn{5}{|l|}{ Cognitive performance } \\
\hline CNB z-score* & $0.38(0.47)$ & $-0.04(0.52)$ & $-0.04(0.53)$ & $-0.18(0.62)$ \\
\hline \multicolumn{5}{|l|}{ Clinical symptoms } \\
\hline Current nicotine use & $25.00 \%$ & $17.65 \%$ & $28.57 \%$ & $30.43 \%$ \\
\hline CAINS MAP* & $0.82(0.40)$ & $1.82(0.71)$ & $1.90(0.67)$ & $1.46(0.67)$ \\
\hline $\mathrm{CDSS}^{* \mathrm{~b}}$ & $0.32(1.38)$ & $11.71(3.14)$ & $11.05(4.42)$ & $2.95(2.70)$ \\
\hline SAPS $* b$ & $0.11(0.47)$ & $0.53(1.33)$ & $1.52(2.34)$ & $4.45(4.15)$ \\
\hline SANS $* b$ & $1.11(2.32)$ & $6.18(2.27)$ & $6.86(2.50)$ & $7.91(4.31)$ \\
\hline \multicolumn{5}{|l|}{ Medication } \\
\hline Typical antipsychotics* & $0 \%$ & $0 \%$ & $0 \%$ & $21.74 \%$ \\
\hline Atypical antipsychotics* & $0 \%$ & $0 \%$ & $42.86 \%$ & $82.61 \%$ \\
\hline Benzodiazepines & $0 \%$ & $17.65 \%$ & $23.81 \%$ & $21.74 \%$ \\
\hline Lithium* & $0 \%$ & $5.88 \%$ & $52.38 \%$ & $0 \%$ \\
\hline $\begin{array}{l}\text { Mood stabilizing } \\
\text { anticonvulsants* }\end{array}$ & $0 \%$ & $0 \%$ & $33.33 \%$ & $8.70 \%$ \\
\hline Other anticonvulsants & $0 \%$ & $5.88 \%$ & $4.76 \%$ & $4.35 \%$ \\
\hline Antidepressants* & $0 \%$ & $58.82 \%$ & $23.81 \%$ & $47.83 \%$ \\
\hline Stimulants & $0 \%$ & $11.76 \%$ & $4.76 \%$ & $8.70 \%$ \\
\hline Anticholinergic & $0 \%$ & $5.88 \%$ & $0 \%$ & $8.70 \%$ \\
\hline Other* & $0 \%$ & $41.18 \%$ & $28.57 \%$ & $13.04 \%$ \\
\hline
\end{tabular}


Table 2. Beta coefficients and standard errors from linear regression models (dependent variable $=$ beta coefficients for DV in the vmPFC)

\begin{tabular}{lccc}
\hline & Model 1 & Model 2 & Model 3 \\
\hline CAINS MAP & $-0.27(0.11)^{*}$ & $-0.32(0.13)^{*}$ & $-0.33(0.15)^{*}$ \\
Primary diagnosis & - & & \\
MDD & - & $0.14(0.15)$ & $-0.08(0.26)$ \\
BD & - & $-0.16(0.14)$ & $-0.22(0.25)$ \\
SCZ & - & - & $-0.20(0.20)$ \\
CNB & - & - & $0.13(0.13)$ \\
Smoke & - & - & $0.14(0.12)$ \\
Severity of illness & - & - & $0.32(0.24)$ \\
CDSS & - & - & $0.07(0.15)$ \\
SAPS & - & - & $-0.03(0.16)$ \\
SANS & - & - & $-0.30(0.12)^{*}$ \\
Task performance & - & $-0.08(0.13)$ \\
Log 10 & $k)$ & & \\
Tjur's $D$ & &
\end{tabular}


bioRxiv preprint doi: https://doi.org/10.1101/2020.12.01.407197; this version posted December 2, 2020. The copyright holder for this preprint (which was not certified by peer review) is the author/funder, who has granted bioRxiv a license to display the preprint in perpetuity. It is made available under aCC-BY-ND 4.0 International license.

\section{Figure 1.}

A

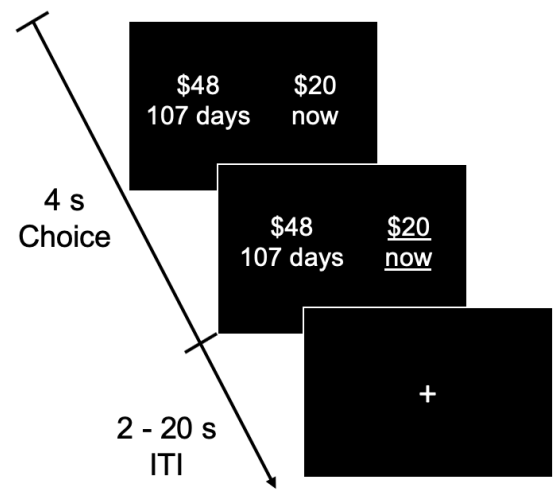

B

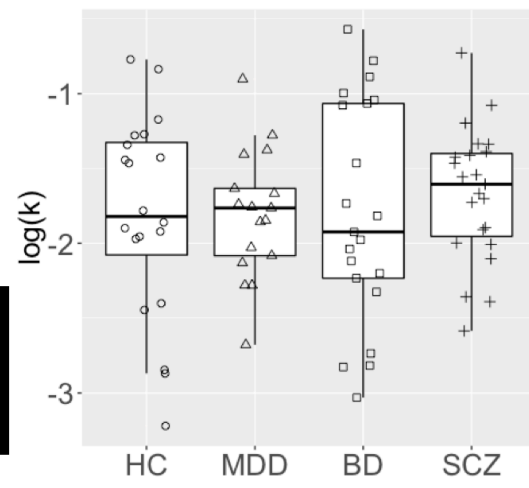

C

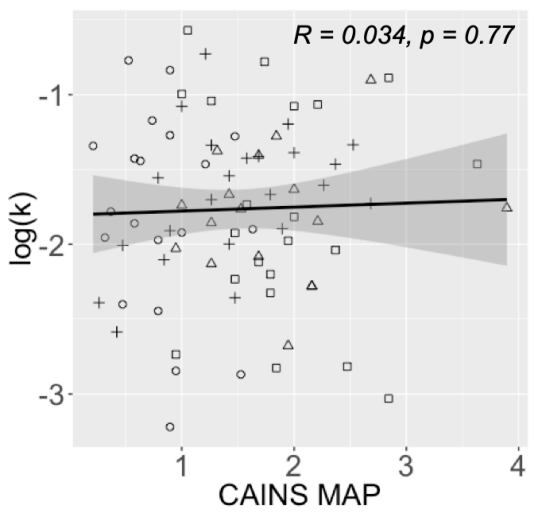


bioRxiv preprint doi: https://doi.org/10.1101/2020.12.01.407197; this version posted December 2, 2020. The copyright holder for this preprint (which was not certified by peer review) is the author/funder, who has granted bioRxiv a license to display the preprint in perpetuity. It is made available under aCC-BY-ND 4.0 International license.

Figure 2.

A

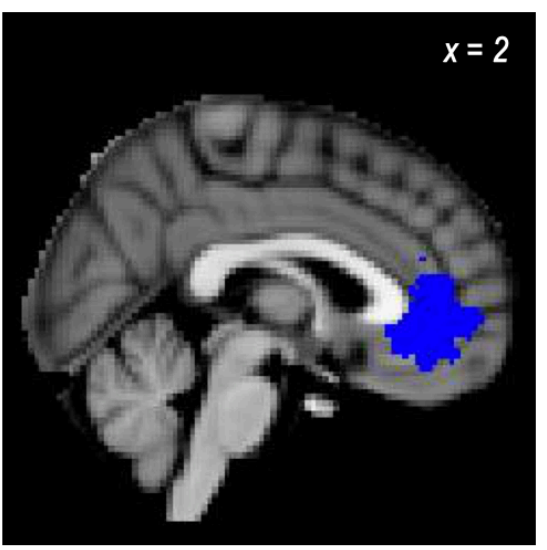

C

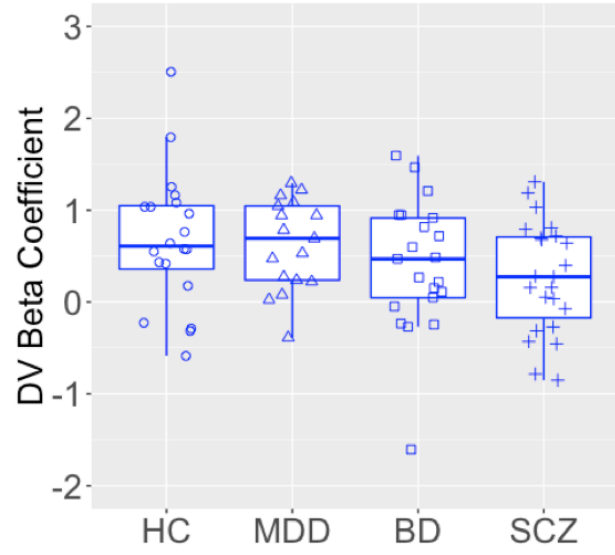

E

3.

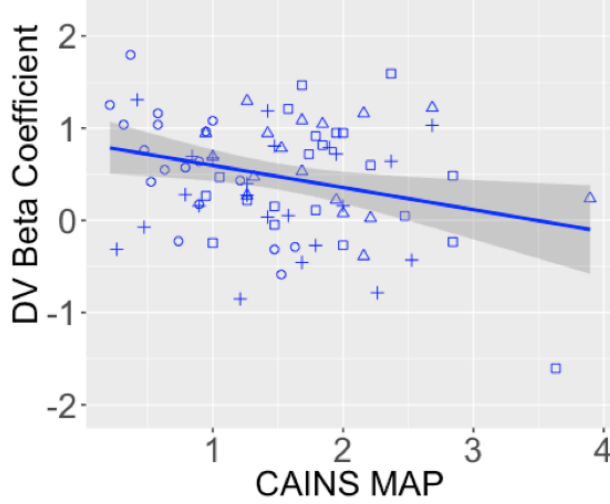

B

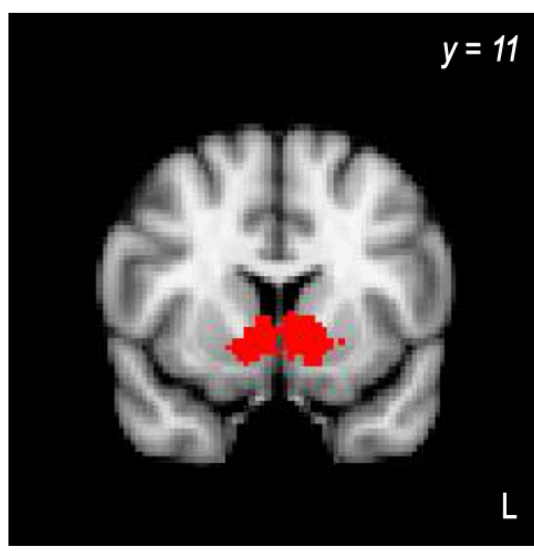

D

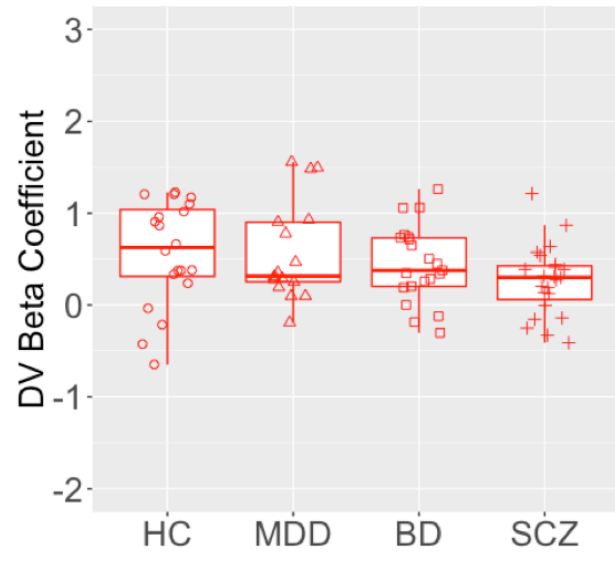

F

3. $R=-0.10, p=0.36$

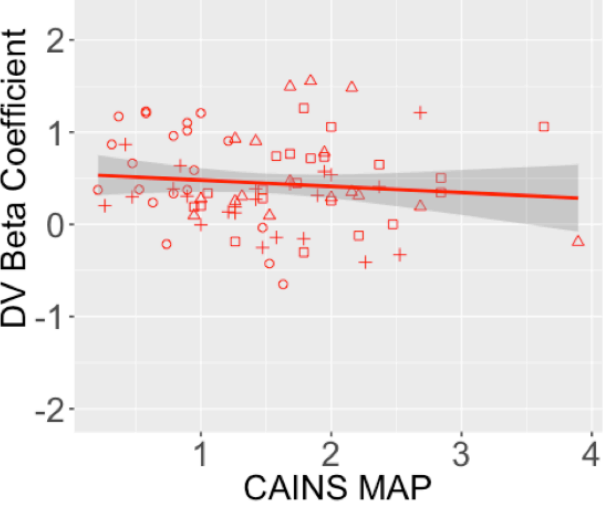


bioRxiv preprint doi: https://doi.org/10.1101/2020.12.01.407197; this version posted December 2, 2020. The copyright holder for this preprint (which was not certified by peer review) is the author/funder, who has granted bioRxiv a license to display the preprint in perpetuity. It is made available under aCC-BY-ND 4.0 International license.

\section{Figure 3.}

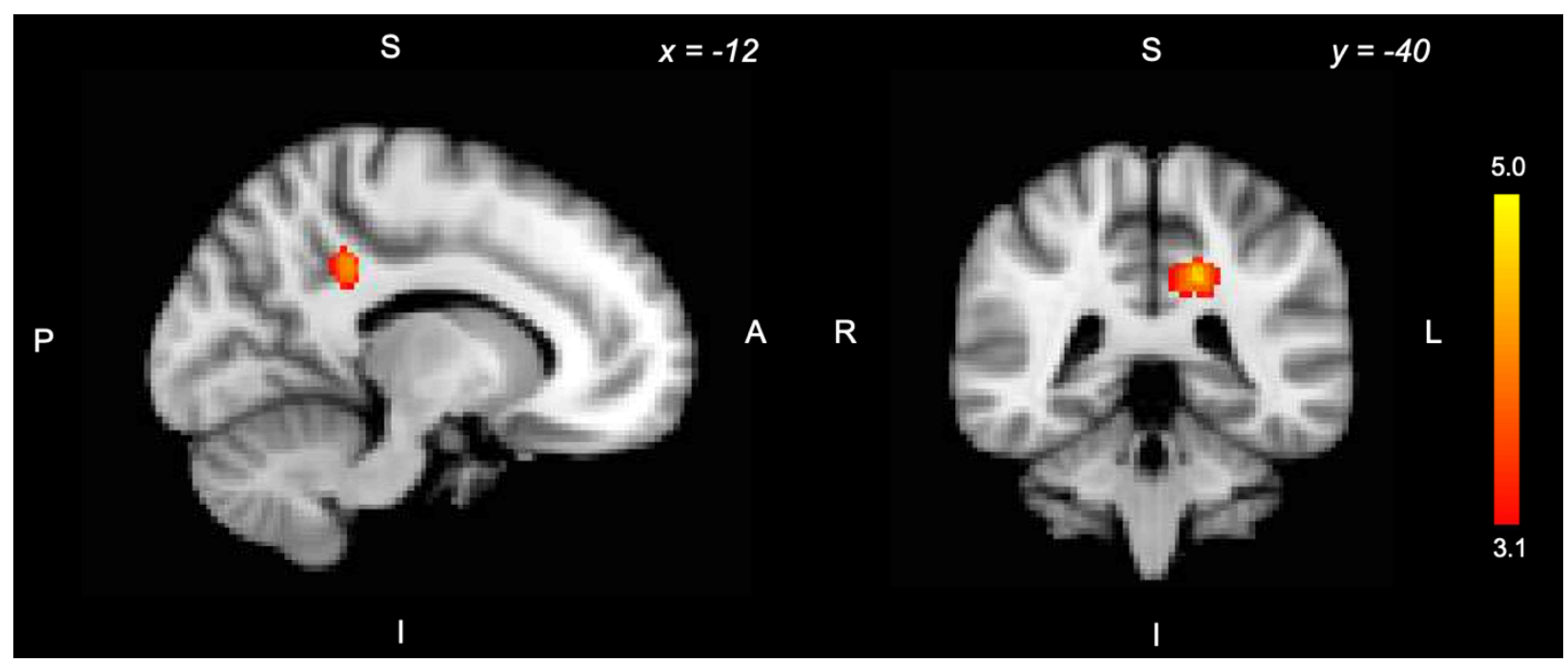




\section{Supplementary Material for}

Decision value signals in the ventromedial prefrontal cortex and anhedonia across mood and psychotic disorders

Min Su Kang, MA ${ }^{1 *}$, Daniel H. Wolf, MD, $\mathrm{PhD}^{2}$, Rebecca Kazinka, MA ${ }^{1,3}$, Sangil Lee, MA ${ }^{1}$, Kosha Ruparel, $\mathrm{MSE}^{2}$, Mark A. Elliott, $\mathrm{PhD}^{4}$, Claudia F. Baldassano, $\mathrm{MD}^{2}$, Anna Xu, $\mathrm{BS}^{2}$, Matthew Cieslak, $\mathrm{PhD}^{2}$, Greer Prettyman, $\mathrm{MS}^{2}$, Theodore D. Satterthwaite, $\mathrm{MD}^{2,5}$, and Joseph W. Kable, $\mathrm{PhD}^{1}$

${ }^{1}$ Department of Psychology, University of Pennsylvania

${ }^{2}$ Department of Psychiatry, Perelman School of Medicine

${ }^{3}$ Department of Psychology, University of Minnesota

${ }^{4}$ Department of Radiology, University of Pennsylvania

${ }^{5}$ Penn-CHOP Lifespan Brain Institute

*Corresponding author:

Min Su Kang, MA

Department of Psychology

University of Pennsylvania

3700 Hamilton Walk

Philadelphia, PA 19104

minskang@sas.upenn.edu 


\section{Supplementary Methods and Materials}

\section{Computerized Neurocognitive Battery}

The following tasks from the Penn Computerized Neurocognitive Battery (CNB) were administered (neurobehavioral function; domain) (1): Penn Face Memory (episodic memory; face memory), Short Penn Continuous Performance Test (executive control; attention), Penn Emotion Recognition Test (social cognition; emotion identification), Penn Word Memory (episodic memory; verbal memory), Short Letter N-back (executive control; working memory), Short Penn Line Orientation Test (complex cognition; spatial ability), Short Penn Conditional Exclusion Task (executive control; mental flexibility), Short Penn Logical Reasoning Test (complex cognition, language reasoning). 
Supplemental Table S1. Intercorrelation of confound variables.

\begin{tabular}{lcccccc}
\hline & 1 & 2 & 3 & 4 & 5 & 6 \\
\hline 1. CAINS MAP & - & & & & & \\
2. CNB & $-0.34^{* *}$ & - & & & & \\
3. Smoke & $0.27^{*}$ & -0.20 & - & & & \\
4. CDSS & $0.54^{* * *}$ & -0.20 & 0.09 & - & & \\
5. SAPS & 0.14 & -0.10 & 0.20 & 0.09 & - & \\
6. SANS & $0.51^{* * *}$ & $-0.29^{*}$ & $0.25^{*}$ & $0.29^{*}$ & $0.40^{* * *}$ & - \\
\hline
\end{tabular}

Note: CAINS MAP = motivation and pleasure, $\mathrm{CNB}=$ average $\mathrm{z}$-score on the Penn Computerized Neurocognitive Battery, Smoke $=1$ for smoker, 0 for non-smoker, CDSS = Calgary Depression Scale for Schizophrenia, SAPS $=$ Scale for the Assessment of Positive Symptoms, SANS $=$ Scale for the Assessment of Negative Symptoms.

$$
\begin{aligned}
& * p<0.05 \\
& * * p<0.01 \\
& * * * p<0.001
\end{aligned}
$$


Supplemental Table S2. Comparison of beta coefficients and standard errors for anhedonia (CAINS MAP) from linear regression models in subsamples excluding participants on each class of medications (dependent variable = beta coefficients for DV in the vmPFC).

\begin{tabular}{lcccc}
\hline Sample & $\mathrm{N}$ & $\beta_{\text {Model } 1}$ & $\beta_{\text {Model } 2}$ & $\beta$ Model 3 \\
\hline Full sample & 81 & $-0.27(0.11)^{*}$ & $-0.32(0.13)^{*}$ & $-0.33(0.15)^{*}$ \\
Subsample excluding & & & & \\
$\quad$ Typical antipsychotics & 76 & $-0.30(0.11)^{*}$ & $-0.40(0.13)^{* *}$ & $-0.39(0.15)$ \\
$\quad$ Atypical antipsychotics & 53 & $-0.24(0.14)$ & $-0.32(0.18)$ & $-0.50(0.19)^{*}$ \\
Benzodiazepines & 68 & $-0.34(0.12)^{*}$ & $-0.35(0.14)^{*}$ & $-0.36(0.16)^{*}$ \\
$\quad$ Lithium & 69 & $-0.32(0.12)^{* *}$ & $-0.36(0.14)^{*}$ & $-0.36(0.17)^{*}$ \\
Mood stabilizing & 72 & $-0.37(0.11)^{* *}$ & $-0.44(0.13)^{* *}$ & $-0.44(0.15)^{* *}$ \\
$\quad$ anticonvulsants & & & & \\
Other anticonvulsants & 78 & $-0.31(0.11)^{* *}$ & $-0.36(0.13)^{* *}$ & $-0.38(0.14)^{*}$ \\
$\quad$ Antidepressants & 55 & $-0.34(0.13)^{*}$ & $-0.44(0.16)^{* *}$ & $-0.54(0.17)^{* *}$ \\
Stimulants & 76 & $-0.27(0.11)^{*}$ & $-0.31(0.14)^{*}$ & $-0.36(0.16)^{*}$ \\
Anticholinergic & 78 & $-0.30(0.11)^{* *}$ & $-0.38(0.13)^{* *}$ & $-0.37(-0.14)^{*}$ \\
$\quad$ Other & 65 & $-0.38(0.12)^{* *}$ & $-0.38(0.14)^{* *}$ & $-0.36(0.16)^{*}$ \\
\hline
\end{tabular}

Note: Independent variables for each model were the following.

Model 1: CAINS MAP

Model 2: CAINS MAP + Primary diagnosis

Model 3: CAINS MAP + Primary diagnosis + CNB + Smoke + CDSS + SAPS + SANS +

$\log _{10}(k)+$ Tjur's $D$

CAINS MAP $=$ motivation and pleasure, $\mathrm{CNB}=$ average $\mathrm{z}$-score on the Penn Computerized Neurocognitive Battery, Smoke $=1$ for smoker, 0 for non-smoker, CDSS $=$ Calgary Depression Scale for Schizophrenia, SAPS = Scale for the Assessment of Positive Symptoms, SANS = Scale for the Assessment of Negative Symptoms, $\log _{10}(k)=$ subject-specific parameter for discount rate, Tjur's $D=$ Tjur's coefficient of discrimination

$* p<.05$.

$* * p<.01$. 
bioRxiv preprint doi: https://doi.org/10.1101/2020.12.01.407197; this version posted December 2, 2020. The copyright holder for this preprint (which was not certified by peer review) is the author/funder, who has granted bioRxiv a license to display the preprint in perpetuity. It is made available under aCC-BY-ND 4.0 International license.

Supplemental Figure S1. Positive effect of decision value. Across all participants, the decision value of delayed rewards was correlated with activity in widespread regions, including vmPFC, ventral striatum, and $\mathrm{PCC}(Z>3.1, p=0.05$, FWE corrected).

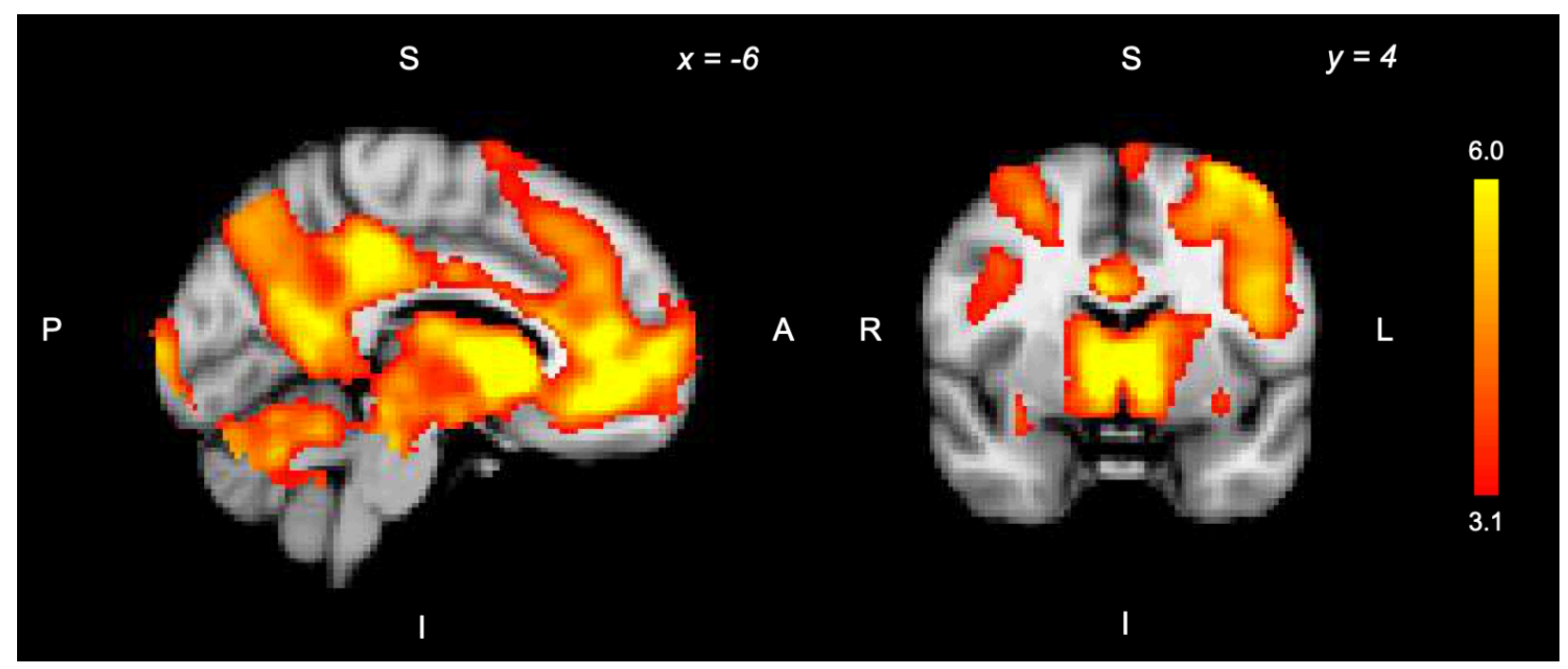


bioRxiv preprint doi: https://doi.org/10.1101/2020.12 01.407197; this version posted December 2, 2020. The copyright holder for this preprint

(which was not certified by peer review) is the author/funder, who has granted bioRxiv a license to display the preprint in perpetuity. It is made available under aCC-BY-ND 4.0 International license.

\section{References}

1. Moore TM, Reise SP, Gur RE, Hakonarson H, Gur RC. Psychometric properties of the Penn Computerized Neurocognitive Battery. Neuropsychology. 2015;29(2):235-46. 